\title{
Poesia, ritual i cant per a la festa: l'univers creatiu i festiu dels poemes de vesticions i professions al convent de carmelites descalces de Barcelona (segle XVII)
}

\section{Poetry, ritual and chant for celebrations: the creative and festive universe of the poems of vesticions and professions in the convent of Discalced Carmelites of Barcelona (17th century)}

\author{
Verònica Zaragoza GÓMeZ \\ veronica.zarago@gmail.com \\ Universitat Oberta de Catalunya \\ Universitat de Girona
}

\begin{abstract}
Resum: En aquest treball analitzem les composicions escrites per a les cerimònies de presa d'hàbit i vel i la professió solemne al convent de la Immaculada Concepció de Barcelona. Aquests poemes amb què les religioses deixaven enrere la seva vida seglar i inauguraven un nou camí com a esposa de Jesucrist, amb una nova identitat construïda en la clausura, formen part d'un dels "subgèneres" poètics més importants $\mathrm{i}$ amb una presència més arrelada en la tradició poètica carmelitana femenina. Per a estudiar-los, en primer lloc, oferim una caracterització general necessària dels usos i funcions de la poesia i el cant al Carmel Descalç femení, aspecte que rarament havia estat tractat des d'una perspectiva catalana. En segon lloc, presentem i emmarquem un corpus tancat de vint-i-cinc composicions inèdites sobre vesticions i professions, que foren escrites per les monges mateixes i copiades posteriorment en el manuscrit de les carmelites descalces de Barcelona, recentment exhumat. N'analitzem les formes d'expressió poètica i els temes presents, per tractar d'extreure'n una identitat femenina carmelitana en el marc d'una tradició hispànica més àmplia.
\end{abstract}

Paraules clau: Teresa d'Àvila, poesia carmelitana, manuscrits, àmbit català

\begin{abstract}
In this essay we address one of the most important poetic subgenres in the tradition of Carmelite women: the works composed for ceremonies of vestition and solemn profession in which the nuns left behind his mundane life and opened a new life as the wife of Jesus. First of all, we provide a general overview of the customs and functions of the poetry in the Discalced Carmelites, which has been already analysed in the context of the Hispanic literature, but rarely from the perspective of the Catalan area. Secondly, we present and contextualize a corpus of twenty-five unpublished compositions on vestitions and professions, copied in the manuscript of the Discalced Carmelites of Barcelona.
\end{abstract}

Keywords: Teresa d’Àvila, Carmelite Poetry, Manuscripts, Catalan area 
Verònica Zaragoza Gómez. Poesia i cant per a la festa: revisió de les composicions creades amb motiu de vesticions i professions al convent de carmelites descalces de Barcelona (segle XVII).

\section{Introducció: la poesia popular en el Carmel Descalç sota el signe de l'alegria i la devoció}

Certament, els manuscrits poètics i les referències documentals que s'han descobert en els darrers anys en arxius carmelitans femenins de l'àmbit català, ens proporcionen un valuós $i$ interessant quadre de l'amalgama de manifestacions culturals que, fusionades al servei de la devoció comunitària, van formar part de la quotidianitat i de l'ambient festiu dels convents de carmelites descalces a l'època moderna (Zaragoza [en premsa] i 2016; Gras 2013 i Diccionar); alhora ens permeten de visualitzar en el seu conjunt un ric ambient cultural i literari en els convents femenins de l'àrea catalana que havia romàs a la penombra fins ara. Alguns dels manuscrits recentment descoberts en aquest panorama són el cançoner poètic del convent de carmelites descalces de la Immaculada Concepció de Barcelona, que hem abordat i editat en la nostra tesi, i els quatre cançoners del convent de carmelites descalces de Santa Teresa de Vic, sobre els quals s'estan realitzant àmplies investigacions amb una mirada interdisciplinar. ${ }^{1}$ Gràcies a aquests tresors, doncs, s'adverteix com, més enllà de l'abundant ús de l'escriptura que caracteritza l'orde carmelità, la poesia en la forma cantada (coplas i villancicos, als quals ens referirem al llarg del treball en les formes catalanes cobles i villancets) ${ }^{2}$ i, sovint, contrafeta al diví, acompanyada d'instruments populars, les danses $i$ les representacions van tenir una presència constant en la vida diària de les religioses; especialment, en el moment de les recreacions i en les festivitats internes. ${ }^{3}$

Pel que fa al conreu i desenvolupament de la poesia conventual femenina -que en els darrers anys ha centrat l'interés de bona part de la crítica- ${ }^{4}$ és de sobra conegut que va comportar una prolífica i intensa activitat literària al Carmel Descalç, amb un origen vinculat a la tasca de difusió del renovament espiritual de Teresa de Jesús, ${ }^{5}$ tal com ens recorda l'especialista Orozco:

\footnotetext{
Todos estos versos hechos para la vida conventual y en concreto para mover a devoción o alegrar a sus monjas forzosamente tenían que responder a la función o necesidad práctica ocasional que cumplían y atender a la mentalidad y escasa formación de la mayoría de estas religiosas que, dada la procedencia de muy buena parte de ellas, se regocijarían más con los versos que sonasen a los ritmos y letras populares de lo que habían escuchado en el mundo. Se explica así, el carácter popular y tradicional de la métrica empleada. (1981: 170)
}

\footnotetext{
1 Vegeu-ne el treball que els ha dedicat Eulàlia Pessarrodona en aquets mateix monogràfic, des de la perspectiva musical.

2 El DIEC els recull, respectivament, com a «Composició poètica breu que serveix comunament de lletra a una cançó popular» $\mathrm{i}$ «Cançó breu d'origen o d'imitació popular, acompanyada d'estrofes, característica de la poesia castellana i tractada polifònicament durant el Renaixement».

3 De fet, en una visita recent al convent de Santa Teresa de Vic, hem pogut comprovar que aquestes pràctiques culturals hi són molt presents.

4 Acabem de defensar la nostra tesi doctoral «En vers vull desafiar...». La poesia femenina a l'àmbit català (segles XVI-XVIII), Edició crítica (2016), dedicada a l'estudi i edició de poesia seglar i monàstica femenina. Altres treballs de l'àmbit hispànic es poden consultar en el volum de Baranda \& Martín (2014) i, per a Portugal, vegeu el magnífic treball monogràfic d'Isabel Morujão (2013), amb un apartat important dedicat a la poesia 'del quotidià', en què s'inclouen les peces per a entrades i professions de monges (2013: 597-611).
}

5 Orozco (1959: 139-150; i 1987) ha documentat magníficament l'activitat poètica a l'entorn de Teresa de Jesús.

SCRIPTA, Revista internacional de literatura i cultura medieval i moderna, núm. 7 / juny 2016 / pp. 160-186 ISSN: 2340-4841 · doi:10.7203/SCRIPTA.7.8475 
Verònica Zaragoza Gómez. Poesia i cant per a la festa: revisió de les composicions creades amb motiu de vesticions i professions al convent de carmelites descalces de Barcelona (segle XVII).

El conreu poètic introduït per l'esperit teresià, acabaria acomplint un paper fonamental en la convivència quotidiana, però també en la vida festiva monàstica femenina durant els segles XVIXviII, fins al punt que s'ha considerat que:

\begin{abstract}
la copla en el ambiente teresiano era de todos los días. Los episodios motivadores se multiplicaban... Tanto las crónicas de la Congregación española y portuguesa, como las biografías de los primitivos religiosos y monjas de la Descalcez, están salpicadas a cada paso de noticias y muestras de incontables poesías originadas o adaptadas a tema religioso (apud. García de la Concha 1970: 377, tot citant Eulogio de la Virgen del Carmen).
\end{abstract}

Per bé que la poesia teresiana va veure la llum tardanament al segle XIX i la seva faceta de poeta ha estat la que menys interés ha despertat en la crítica fins ara (Baranda 2013), ${ }^{6}$ la delectació de la reformadora en la poesia, i el seu discurs a favor del conreu poètic, que llegim dispers en nombrosos fragments de les cartes o del Libro de la Vida teresians, demostren com aquesta va maldar per impulsar la creació i el consum poètics en els convents femenins hispànics, sota el signe de l'alegria i de l'austeritat:

\begin{abstract}
Gustaba la Madre de que sus monjas anduvieran alegres y que cantasen en las fiestas de los santos e hiciesen coplas. Mas como gustaba de dar ejemplo en todo, hacíalas ella misma y las cantaba en unión de sus hijas sin instrumento ninguno de música, sino acompañándose con la mano, dando ligeras y suaves palmadas para llegar al compás y hacer cierta armoniosa cadencia (cfr. Manero 1991: 39).
\end{abstract}

Amb aquest conegudíssim fragment, Francisco de Ribera, el primer biògraf de Teresa, que la va conèixer i tractar, donava sonada notícia de l'afecció de la reformadora per la poesia, acompanyada d'instruments musicals humils, sovint els més austers: les palmes, «signo instrumental de desnudez y pobreza; la danza, dinámica jubilosa del arrebato místico» (Manero 1991: 30). Aquest corrent poètic, de base tradicional i via cantada practicat en l'ambient carmelità descalç, té els seus orígens en el segle $\mathrm{XV}$ als ordes franciscà i jerònim, amb la presència de poetes espirituals d'anomenada com ara el mateix sant Francesc d'Assís, fra Ambrosio de Montesino, per al primer orde, i fra Hernando de Talavera, i Álvarez Gato, per al segon (Orozco 1959: 121-134) que seran imitats al segle xvi en ple ambient de reforma per alguns carmelites encarregats d'assentar la tradició: parlem de Teresa de Jesús, pel que fa a la línia femenina, i de Juan de la Cruz que, com aquella, també va impulsar els religiosos a la cançó i a la improvisació. En general, la promoció del conreu poètic i del cant per part de la fundadora en els convents carmelitans femenins ${ }^{7}$ responia a un intent d'instaurar la poesia com a eina fonamental de sociabilitat

6 Quant a la problemàtica d'estudi de la poesia teresiana, lleg. Ruiz (1990); respecte a la personalitat literària de santa Teresa, són nombrosos els treballs apareguts darrerament, veg. l’estudi ja clàssic de García de la Concha (1977).

7 Per a les qüestions relatives a l'activitat poètica del Carmel, vegeu Orozco (1959; esp. capítol «Poesía tradicional carmelitana», p. 112-170 i 1987; esp. capítol «La poesía de Santa Teresa y el ambiente conventual carmelitano», p. 115177), García de la Concha \& Álvarez Pellitero (1982), i Álvarez Pellitero (1983). Entre la nombrosa bibliografia dedicada a aquesta tradició carmelitana, vegeu el complet assaig d'Emeterio de Jesús Maria (1949), que proporciona també un 
Verònica Zaragoza Gómez. Poesia i cant per a la festa: revisió de les composicions creades amb motiu de vesticions i professions al convent de carmelites descalces de Barcelona (segle XVII).

en la vida conventual reformada, que no només afavoriria el recolliment espiritual, sinó també facilitava l'expressió a l'ànima, en l'experiència de cant transformada en experiència mística (Orozco 1987: 117):

\begin{abstract}
¡Oh, válame Dios cuál está un alma cuando está ansí! Toda ella querría que fuese lenguas para alabar a el Señor; dice mil desatinos santos, atinando siempre a contentar a quien la tiene ansí. Yo sé persona que, con no ser poeta, que le acaecía hacer de presto coplas muy sentidas declarando su pena bien, no hechas de su entendimiento, sino que, para más gozar la gloria que tan sabrosa pena le daba, se quejaba de ella a su Dios (Vida, 16, \4).
\end{abstract}

Possiblement siga aquest el fragment més citat per la crítica, el qual reflecteix la vehemència de la reformadora per introduir-hi l'afició poètica als seus convents, no només com a esbarjo tolerable sinó, fins i tot, aconsellable per al conreu d'aquelles ànimes sofertes en clausura, amb l'objectiu de potenciar un veritable ambient ascètic en el Carmel reformat fonamentat en l'alegria (García de la Concha \& Álvarez Pelliter 1982: IX). Així, ho testimoniava la carmelita Maria de San José Salazar (1548-1603), contemporània i confident de la santa d'Àvila, en el seu Libro de recreaciones: "Todo se pasaba riendo y componiendo romances y coplas de todos los sucesos que nos acontecían, de que nuestra santa gustaba extrañamente, y nos daba mil gracias porque con tanto gusto y contento pasábamos tantos trabajos [...]» (cfr. Herpoel 2013: 243).

I és que, malgrat que la intenció de Teresa de Jesús era instaurar l'observança conventual rigorosa, també era conscient que calia adobar un ambient de convivència monàstica amè, amb espais d'evasió i de recreació que permetessen a les religioses alleugerir una vida conventual regida per unes fèrries normes $\mathrm{i}$ uns horaris estrictes, $\mathrm{i}$ basada en la més severa austeritat. Per fer-ho, Teresa de Jesús va instaurar les anomenades «recreacions», ${ }^{8}$ moments de sociabilitat que solien transcórrer entre cants, converses pies, conferències espirituals o lectures en veu alta, i que, al capdavall, van esdevenir una circumstància idònia per a les manifestacions literàries i culturals de les monges. Aquests espais d'esbarjo foren reglamentats en les primeres Constitucions del convent de San José d’Àvila: un document que havia de regular els aspectes de la vida monàstica de la seva primera fundació - duta a terme el 1562- i que seria després adreçat a la resta de monestirs de l’orde. Ho llegim en els termes següents, a la segona redacció de 1585:

catàleg d'autors i autores de l'orde descalç, i l'estudi fonamental d'Orozco (1959), que tracta la poesia dels místics orientada a Juan de la Cruz, revisat i enriquit amb interessants reflexions per García de la Concha (1976); i Ruiz Pérez (1990). Veg. també Hanna (2015) sobre el panorama de poesia carmelitana francesa.

8 Aquesta noció d'esbargiment la trobem també perfilada al Libro de la Vida i al Camino de la perfección de Teresa de Jesús. És paradigmàtica, en aquest sentit, l'obra manuscrita de l'esmentada sor María de San José, que va escriure un Libro de recreaciones «por ir mezclado con diversas cosas bien semejantes a los entretenimientos de las hermanas, los cuales, compuestos de muchas materias, sacan un fin, que es alabanzas a Dios» (Sánchez 1993: 933). L’ha estudiat Milagros Sánchez (1993), que ofereix una breu introducció a les recreacions del Carmel, a propòsit de l'anàlisi de les tres conferències espirituals «Sobre la recreación» de la beata Ana de San Bartolomé (1549-1626). Sobre l'esmentada María de San José, autora també de poesia, llegiu, p.e., Manero (1992).

SCRIPTA, Revista internacional de literatura i cultura medieval i moderna, núm. 7 / juny 2016 / pp. 160-186 ISSN: 2340-4841 · doi:10.7203/SCRIPTA.7.8475 
Verònica Zaragoza Gómez. Poesia i cant per a la festa: revisió de les composicions creades amb motiu de vesticions i professions al convent de carmelites descalces de Barcelona (segle XVII).

\begin{abstract}
Salidas de comer, podrá la madre priora dispensar que todas juntas puedan hablar en lo que más gusto les diere, como no sean cosas fuera del trato que ha de tener la buena religiosa; y tengan todas allí sus ruecas. Juego en ninguna manera se permita, que el Señor dará gracia a unas para que den recreación a otras. Fundadas en eso, todo es tiempo bien gastado (citat a Baranda 2013: 168).
\end{abstract}

Tot i que, en els seus intents de legislar les primeres comunitats carmelitanes descalces, la reformadora no hi al ludeix directament a la poesia, la pràctica fou una altra: en l'ambient de l'orde, s'hi va acabar instaurant la composició i el cant de cobles i villancetsaixí com les petites representacions devotes vinculades a la vida conventual, ${ }^{9}$ tot emmarcant-se en aquest temps diari d'esbargiment, tan fecund, intel lectualment i culturalment parlant. Així ho llegim, per exemple, al costumari del primer convent de carmelites descalces, Costumbres santas del convento de carmelitas descalzas de San José de Ávila (reproduit pel pare Silverio de Santa Teresa 1935: 765-778) ${ }^{10}$, on trobem detallades les activitats literàries realitzades per les monges de la dita comunitat en el context de les «recreacions»: ${ }^{11}$

En la recreación, una vez a la semana, tenemos conferencia espiritual, para lo cual se escribe en una tablilla el punto sobre el que ha de versar ésta, y nuestra Madre va preguntando a todas, empezando por las mayores, sobre lo que se les ofrece sobre la virtud o punto propuesto. En las recreaciones de Cuaresma nuestra Madre pregunta la Doctrina cristiana a todas las religiosas indistintamente. A principios de mes se sacan los santos Patronos y éstas papeletas las escribe la M. Superiora (Silverio de Santa Teresa 1935: 766).

D'aquest compendi de costums, ens interessa també revisar l'apartat dedicat a las Fiestas que celebramos en esta santa casa, una font documental cabdal que ens permet resseguir de quina manera la poesia, des de la seva vessant cantada, se la dota d'un paper fonamental en algunes cerimònies més o menys ritualitzades de la comunitat carmelitana de San José: el Nadal, el dia del Nen perdut, el Dijous Sant, el diumenge de Resurrecció, el dia de sant Bartomeu, el diumenge de l'octava de Nostra Senyora

9 Les fonts documentals conegudes que ens permeten documentar pràctiques dramatúrgiques escassegen a casa nostra; amb tot existeixen alguns indicis amb què podem plantejar-nos que les interpretacions als convents eren comunes, especialment per les referències que extraiem dels manuscrits que estem estudiant. Per a l'esfera hispànica, Borrego (2014) ha estudiat recentment els textos de tres festes teatrals representades al convent de carmelites descalces de Valladolid (1600-1643) i escrits per María de San Alberto i Cecilia del Nacimiento, les quals van deixar autos, coloquios o fiestas amb motiu del Nadal o festes de professió, estudiades amplament per Arenal \& Schlau (2010: 129-184). Sobre el gènere del teatre conventual femení, veg. els treballs de Carmen Alarcón (2000 i 2004). En relació a l’orde carmelità que ara ens ocupa, l'estudiosa explica que «Hacia 1675, en las carmelitas de San José, se llevó a escena un coloquio para celebrar la beatificación de San Juan de la Cruz, escrito por Sor Gregoria Francisca de Santa Teresa [no conservada]» (Alarcón 2004: 184).

10 Es tracta del vol. II, dedicat a «Santa Teresa en San José de Ávila (1562-1567)»; llegim el costumari als apèndixs al capítol XXX: I «Costumbres santas... » i II «Costumbres santas del noviciado...».

11 No sabem concretament quan va ser escrit; només sabem que és posterior a la mort de Teresa de Jesús (1582). Interessa per a les nostres reflexions perquè recull les tradicions de la comunitat, que s'haurien perpetuat al llarg dels segles, com ocorre amb d'altres documents semblants (és el cas del costumari de les carmelites descalces de Barcelona, com veurem a continuació, escrit al segle xx però amb referències a les tradicions antigues de la comunitat que encara s'hi mantenen).

SCRIPTA, Revista internacional de literatura i cultura medieval i moderna, núm. 7 / juny 2016 / pp. 160-186 ISSN: 2340-4841 · doi:10.7203/SCRIPTA.7.8475 
Verònica Zaragoza Gómez. Poesia i cant per a la festa: revisió de les composicions creades amb motiu de vesticions i professions al convent de carmelites descalces de Barcelona (segle XVII).

Mare, el dia de l'Esperit Sant, el dia de l'Encarnació, el dia de l'Assumpció... que solien incloure com a part puntal dels actes, el cant de versos tradicionals (villancicos o coplas), propis del dia o creats exprofeso per les religioses amb més perícia, acompanyats per instruments. ${ }^{12}$ Ho llegim, per exemple, en una de les cartes de Teresa de Jesús, adreçada al seu germà Lorenzo de Cepeda, el 1577:

\begin{abstract}
Gran fiesta tuvimos ayer con el nombre de Jesús [la Circumcissio]: Dios se lo pague a vuestra merced. No sé qué le envíe por tantas como me hace, si no esos villancicos, que hice yo, que me mandó el confesor las regocijase [les monges] y he estado estas noches con ellas [s' entén que en la recreacio], y no supe cómo, sino ansí. Tienen graciosa sonada, si la atinare Francisquito [el seu nebot], para cantar. Mire si ando bien aprovechada (reproduïda per Menéndez Pidal 1992: 126-130).
\end{abstract}

En els nostres estudis sobre el cançoner de les carmelites descalces de Barcelona (Zaragoza 2016 i [en premsa]), ja vam advertir que bona part de la poesia recollida en el manuscrit (almenys la de creació pròpia, juntament amb la que va tenir una vida més efímera perquè no s'hi va copiar) s'havia de contextualitzar en aquest ambient festiu i devocional del convent. Un univers privat, personal i íntim al qual hem pogut accedir, també gràcies al costumari de la comunitat, gràcies al quadern Breves apuntes de las fiestas y santas costumbres que teniamos en el Carmelo de la Calle Canuda de Barcelona ${ }^{13}$ (Zaragoza [en premsa]), que dóna testimoniatge sobre els costums i les celebracions del convent antic perpetuats al llarg dels segles. ${ }^{14}$ A través d'aquest document, doncs, s'hi constata que la poesia (sovint amb esquemes de dramatització), les representacions i el ball eren activitats preuades per a celebrar el Nadal -vehiculades en la coneguda tradició de les «Posadas»-, l'Exaltació de la Creu (setembre), amb un desafío de virtudes o la «fiesta tan simpática de Santa Bárbara» (agost)...

Amb això, podem suposar que aquestes tradicions festives eren semblants en els convents del mateix orde carmelità i imaginem que no podien estar massa allunyades del que s'esdevenia en convents d'altres ordes, pel fet que imperaven uns paràmetres de religiositat més o menys semblants. De fet, amb la mateixa intensitat, aquests cants devots també tenien un paper important de canalització dels efluvis devots i amorosos (sagrats) en ambients externs als convents, amb una important funció didàctica, independentment dels ordes o tradicions espirituals. Ho veiem, per exemple, amb el cas de la noble valenciana Eugènia Salzedo i Salazar (Alzira, 1579-Tortosa, 1645) que, en enviduar del marit, va prendre l'hàbit de terciària franciscana i, després de deixar els fills amb tutors, es va establir a Tortosa, on va exercir de mestra amb nenes pobres, a les quals feia cantar càntics divins:

Tenía especial consuelo esta sierva de Dios en oír cantar las divinas alabanzas y, puesta en el retiro de su casa, su recreación era cantar algunas letras a Christo su esposo y a la santíssima

12 Així ho assenyalen, d'altra banda, les rúbriques de nombroses composicions que expliciten per a quina circumstància específica foren creades, en el marc d'aquest costum de poetització.

13 Arxiu Carmelites Descalços de Catalunya i Balears, Ms. [s.sign.].

14 En l'actualitat la comunitat viu al barri barceloní de Sant Gervasi.

SCRIPTA, Revista internacional de literatura i cultura medieval i moderna, núm. 7 / juny 2016 / pp. 160-186 ISSN: 2340-4841 · doi:10.7203/SCRIPTA.7.8475 
Verònica Zaragoza Gómez. Poesia i cant per a la festa: revisió de les composicions creades amb motiu de vesticions i professions al convent de carmelites descalces de Barcelona (segle XVII).

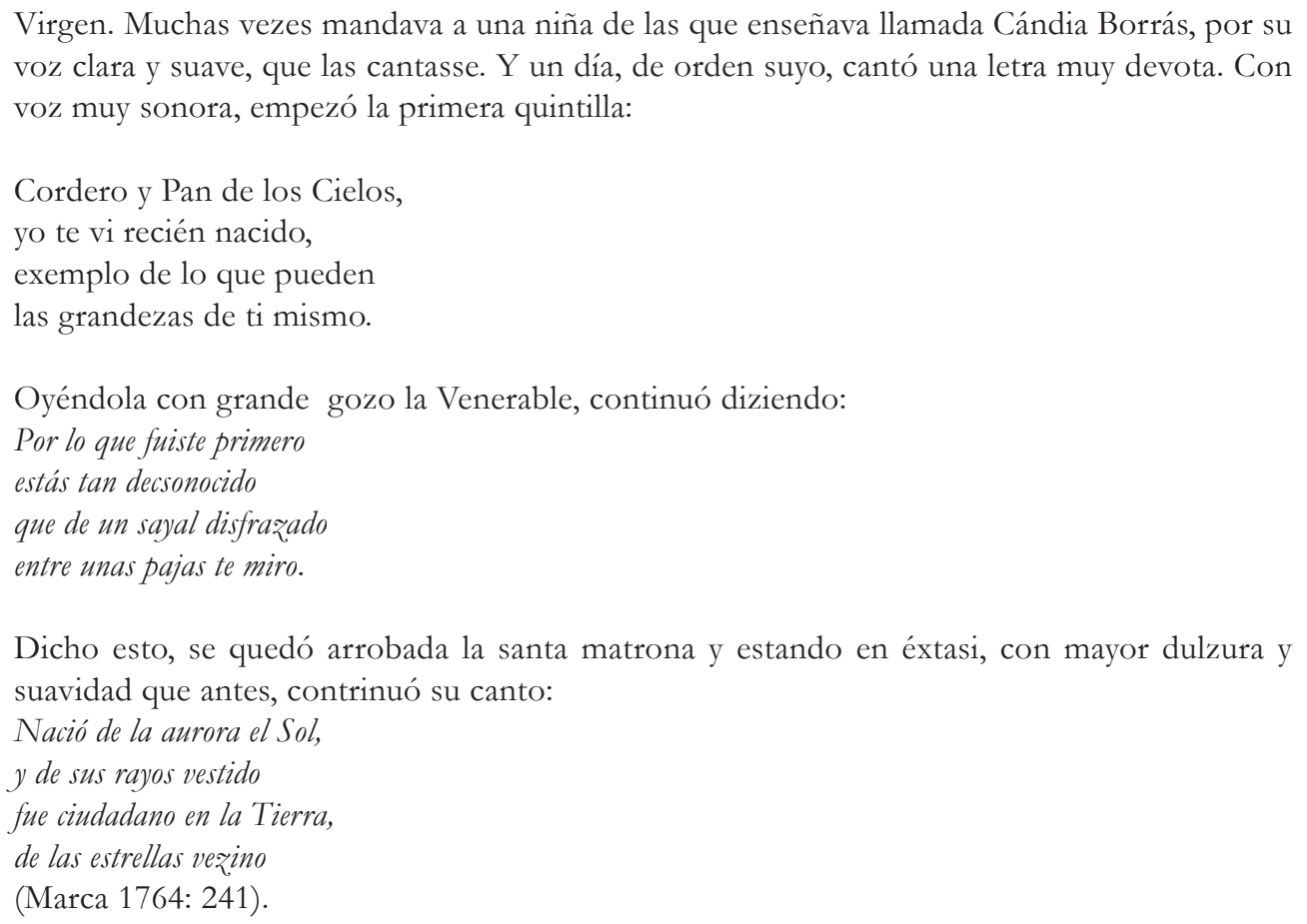

Aquests materials que acabem de referir són fonamentals perquè ens forneixen algunes dades de detall (que usualment escassegen) amb què accedim al món privat de les comunitats carmelites, i visualitzem la presència dels versos en unes circumstàncies determinades; allò que García de la Concha \& Álvarez defineixen com a «ocasiones conventuales propicias a la poetización» (1982: XI) i que cal conèixer per a poder contextualitzar i proporcionar una bona interpretació i valoració de la poesia carmelitana. Adduïa Orozco, a propòsit de la poesia teresiana que: «Desligar su obra poética de la circunstancia espiritual extraordinaria o -más frecuentemente- de la actividad cotidiana de la vida conventual impediría comprenderla, caracterizarla y valorarla debidamente» (Orozco 1987: 119). I més endavant, l'estudiós encara defensava que:

Hay, pues, que pensar que el por qué, para qué, y para quién se crea esta poesía, aún la de expresión más personal y elevada, responde y queda totalmente dentro del ambiente conventual carmelitano como canto que seguidamente se repite colectiva y aisladamente entre las monjas y que después pasó también en algunos casos a los religiosos quienes para adaptarla a la expresión masculina introducen en algunas ocasiones algunas variantes (Orozco 1987: 123).

Per això considerem que és important reflexionar sobre el perquè de la creació de versos als convents i interrogar-nos sobre els ambients de creació i recepció de les peces, que solien anar adreçades a les religioses mateixes (tot i que el material podia circular manuscrit entre els convents de l'orde) en les circumstàncies festives. En l'ambient conventual, aquestes ocasions eren, generalment, els moments 
Verònica Zaragoza Gómez. Poesia i cant per a la festa: revisió de les composicions creades amb motiu de vesticions i professions al convent de carmelites descalces de Barcelona (segle XVII).

d'esbarjo i també les festivitats pròpies del Cicle litúrgic o calendari festiu, ${ }^{15}$ en què la poesia hi feia presència amb l'objectiu d'alegrar l'ambient devotament (Gras 2013: 316-319; Herpoel 2013: 246), però també per a solemnitzar visites importants o celebrar festes extraordinàries relacionades amb la «família espiritual», com ara l'elecció de priores o les professions i preses d'hàbit de les religioses, «Fiestas especialísimas [...] que se celebraban con la misma alegría que cualquier otra boda de la época, y para las que se han conservado buen número de coplas, muchas de ellas de santa Teresa» (Zafra 2015: 753). Sobre aquestes 'festes especialíssimes' amb què es celebraven un dels moments més transcendents de les religioses, hi parlarem a continuació.

\section{Les vesticions i professions de religioses: el marc festiu per a una producció poètica rica}

Amb aquestes dades que acabem d'oferir, veiem com en els convents de carmelites, ja des de l'època de Santa Teresa i per la seva influència, la poesia va esdevenir al llarg dels segles moderns -i encara ho és avui dia-, una eina fonamental d'expressió però també de celebració; creada sovint per a circumstàncies molt concretes i condicionada, per tant, al context d'emissió, tal com ja he anat comentat. Així mateix, adverteix Pedro Ruiz a propòsit de la lírica teresiana -i que podem aplicar a la resta de poesia carmelitana: «La particularidad de la experiencia religiosa de la autora, así como el contexto real en que nace su creación lírica, determina la especificidad de una poesía pensada para su recepción inmediata y muy condicionada por ella» (Ruiz 1990: 186).

Si ens centrem ara en el context de poetització del cicle poètic que estem examinant, les festes celebrades intramurs amb motiu de les professions i vesticions van ser importants cerimònies de poetització i de recepció immediata d'una poesia específicament conventual; una poesia que exercia la seva funció de socialització i que pretenia homenatjar a les religioses recentment ingressades a la família espiritual. Aquesta poesia ens ha arribat, parcialment, gràcies al fet que fou copiada als cançoners col lectius, custodiats als arxius de les comunitats, conformant un cicle clarament diferenciat de la resta de sèries poètiques de la tradició carmelitana (Zaragoza (2016) [en premsa]; García de la Concha \& Álvarez 1982: 92-105; Álvarez 1983). Així doncs, els poemes que estem estudiant respondrien a un subgènere de la poesia conventual freqüentat per les religioses de l'època a tot l'àmbit hispànic; una tradició poètica perpetuada al Carmel, però estesa a la resta d'ordes, a la qual es van dedicar autores de renom, com ara les carmelites descalces Ana de San Bartolomé, María de San José Salazar, Cecilia del Nacimiento o la mateixa Teresa de Jesús, la concepcionista Marcia Belisarda, la dominica Violante de Ceo i la trinitària sor Marcela de San Fèlix (Baranda 2011; Llergo 2016). ${ }^{16}$ Sabem també que algunes composicions creades amb motiu de les mateixes festivitats,

15 Altres fonts accessibles per a l'estudi de les festivitats i solemnitats de l'any litúrgic, amb presència poètica, són les fonts hagiogràfiques, autobiogràfiques i cronístiques. Nieves Baranda (2013) ha pogut documentar pràctiques poètiques conventuals d'algunes religioses de l'època moderna, emmarcades en aquestes festivitats i espigola dades precioses tant en Vides espirituals, com en biografies o memòries.

16 Sobre aquesta composició creada als convents per les religioses per a professions, Alicia Fraschina ha proporcionat

SCRIPTA, Revista internacional de literatura i cultura medieval i moderna, núm. 7 / juny 2016 / pp. 160-186 ISSN: 2340-4841 $\cdot$ doi:10.7203/SCRIPTA.7.8475 
Verònica Zaragoza Gómez. Poesia i cant per a la festa: revisió de les composicions creades amb motiu de vesticions i professions al convent de carmelites descalces de Barcelona (segle XVII).

acostumaven a ser encarregades a autors i músics (masculins) professionals -alguns reconeguts a l'època-, o a amics de la novícia; ${ }^{17}$ tanmateix, pel que observem en l'àmbit carmelità català, bona part d'aquestes peces també van ser creades per a l'ocasió per les religioses mateixes copiades als cançoners col lectius amb el segell característic de l'anonimat. Davant d'aquesta heterogeneïtat en la composició i execució de poesia creada per a vesticions i professions, considerem que, prèviament, convé que revisem el ritual amb què se celebraven aquestes cerimònies per veure'n els diferents graus de sociabilitat en les cerimònies celebrades intramurs, atés que el caràcter privat o públic de les cerimònies -breument esbossada aquí- acabarà determinant els nivells de circulació i de difusió dels materials poètics resultants.

\subsection{Els ritus d'ingrés i professió a la vida conventual carmelitana}

De la revisió dels cerimonials de professions de l'època inferim les pautes i els elements més importants d'aquests ritus amb què la religiosa es consagrava a Déu i inaugurava un nou camí com a esposa de Jesucrist. En aquest sentit, el volum Método de las funciones de ábito, professión y velo de las religiosas carmelitas descalzas, conforme al cerimonial de la misma orden, imprés a València (1772), ofereix informació interessant. ${ }^{18}$ En el Carmel Descalç, el procés d'ingrés al convent constava de tres cerimònies diferenciades: la presa d'hàbit, la professió solemne i la recepció del vel, tres nivells que trobem representats en la sèrie de poemes que estudiem (tal com reflecteixen les rúbriques: «al hábito», «al velo», «a la profesión»).

La presa d'hàbit suposava l'inici del noviciat, un temps de preparació del cos, l'intel lecte i l'ànima de la futura religiosa per a la vida i el ritme conventual. Durant l'any de preparació que solia durar el noviciat (a càrrec de la mestra de novícies), pel que fa a les aptituds intel lectuals, Teresa de Jesús exigia a les postulants «entendimiento» $\mathrm{i}$ «habilidad para rezar el oficio divino y ayudar en el coro», aspecte que requeria tenir nocions de la lectura, que es podien adquirir intramurs juntament amb d'altres capacitats (cfr. Téllez 2013: 69). Quant a la cerimònia amb què es concretava aquest estat,

observacions molt interessants en un article en premsa («Poesía en la clausura. Celebrando el ingreso y la profesión solemne en el Monasterio Santa Catalina de Sena de Buenos Aires: 1861-1903»).

17 P.e., el carmelità descalç fra Antoni del Cor de Santa Teresa, Sala Guàrdia (1727-1805) va escriure textos poètics dedicats a l'ingrés en religió de sis novícies, quatre d'elles carmelites descalces en el convent de la Immaculada Concepció (cfr. Diccionari [s.v. Antoni del Cor de Santa Teresa, Sala Guàrdia (Barcelona, 1727-1805, Mataró)]; de la mateixa estudiosa veg. dues entrades amb títol Resar, recitar i cantar: Poesia per a monges d'Antoni del Cor de Santa Teresa (1727-1805) publicades al bloc Castell Interior [en línia: https://castellinterior.wordpress.com/2015/01/27/resar-recitar-i-cantar-poesia-per-amonges-dantoni-del-cor-de-santa-teresa-1727-1805-1/ i https://castellinterior.wordpress.com/tag/antoni-del-cor-desanta-teresa/[consulta: 29/04/2016].

18 Veg. el treball de Téllez (2013), referit al convent de San José de Mèxic, però amb reflexions aplicables al context general del Carmel Descalç (2013, esp. «III. La muerte al mundo y la construcción de una nueva identidad: 1. El noviciado, 2. La toma de hábito, 3. La profesión, 4. La recepción del velo», p. 68-87).

SCRIPTA, Revista internacional de literatura i cultura medieval i moderna, núm. 7 / juny 2016 / pp. 160-186 ISSN: 2340-4841 · doi:10.7203/SCRIPTA.7.8475 
Verònica Zaragoza Gómez. Poesia i cant per a la festa: revisió de les composicions creades amb motiu de vesticions i professions al convent de carmelites descalces de Barcelona (segle XVII).

la presa d'hàbit, la postulant era rebuda a la porta per la comunitat de religioses i, en processó, l'adreçaven al cor baix, on l'engalanaven amb els seus mants, amb ciris encesos i els rostres coberts amb els vels, a cant d'himne (O Glorioso Virginum). El sacerdot proferia una oració i el bisbe, que presidia la cerimònia, interrogava la postulant, mitjançant la fórmula estereotipada de preguntaresposta que la novícia havia de conèixer, seguit d'una plática exhortativa per part d'aquest amb consells i avisos sobre la vida conventual. A continuació, la postulant era vestida per les seves companyes amb la túnica blanca, la toga i les espardenyes, tres elements característics de l'hàbit del Carmel que eren completats amb la corretja, l'escapulari i la capa. A continuació, la benedicció de la novícia venia acompanyada d'himnes executats per les cantores del convent, i d'altres accions carregades de simbolisme (postració en forma de creu, bes a la priora, abraçada amb les germanes...) que marcaven el temps i el ritus d'aquell moment tan transcendental que podia comptar amb presència de públic, segons l'estatus de la noia, com veurem més endavant.

Per a la professió solemne, la cerimònia repetia els ritus suara assenyalats, però amb un significat diferent ja que, d'entrada, ja no s'hi comptava amb cap autoritat masculina sinó que es tractava d'una cerimònia dirigida per la priora que era qui proferia l'interrogatori i la plática. ${ }^{19}$ A més, a diferència de la cerimònia de la presa d'hàbit, la professió se solia desenvolupar en la més estricta privacitat, davant únicament de la comunitat de religioses, malgrat les referències existents referides al Carmel Descalç que demostren que sí que algunes professions foren celebrades públicament amb el boato corresponent. Seguit dels rituals ja establerts, la futura religiosa havia de signar les cèdules de professió i formalitzar el jurament dels vots de pobresa, castedat i obediència, juntament amb el de la clausura. Aquesta cerimònia anava seguida de campanades que tocaven a difunts, en senyal de l'abandonament del món per part de nova religiosa que deixava enrere la seva identitat per emprendre una nova vida a la clausura. ${ }^{20}$

Finalment, la recepció del vel -sovint confosa amb la cerimònia de professió- era una cerimònia independent amb què culminava el procés de consagració a la vida conventual; una cerimònia pública, d’una gran solemnitat que solia estar presidida per una autoritat pública.

\subsection{Les cerimònies de consagració religiosa com a ritus socials iniciàtics}

Pel que podem llegir a la documentació i en força literatura, és sabut que en bona part dels convents femenins d'època moderna ${ }^{21}$ les professions solemnes es van convertir en ritus iniciàtics de la vida

$19 \mathrm{Al}$ Diccionari de Mercè Gras hi trobem la notícia de plàtiques proferides per priores, que l'estudiosa ha exhumat de l'arxiu del convent de les carmelites descalces de Barcelona.

20 Per aquest motiu, en les cobles dedicades a les professions, la mort de la professa hi apareix com un tema recurrent; veg. Fraschina [en premsa] al qual ja ens hem referit.

21 Per als convents de l'esfera catalana, es refereix a aquesta activitat Serra de Manresa (2002: 152) en relació a les

SCRIPTA, Revista internacional de literatura i cultura medieval i moderna, núm. 7 / juny 2016 / pp. 160-186 ISSN: 2340-4841 · doi:10.7203/SCRIPTA.7.8475 
Verònica Zaragoza Gómez. Poesia i cant per a la festa: revisió de les composicions creades amb motiu de vesticions i professions al convent de carmelites descalces de Barcelona (segle XVII).

conventual i van donar lloc a celebracions de caràcter eminentment social, que podien incorporar a l'element religós, un convit familiar, la interpretació de poesia musicada (cobles) i textos paradramàtics (autos, col loquis, villancets paralitúrgics...), ${ }^{22}$ amb la forma del gènere tradicionals dels villancets i de motlle culte. De fet, Rosa M. Creixell (2012: 130-133) estableix una interessant analogia entre el matrimoni carnal de les dones seglars i el matrimoni espiritual de les dones religioses; en tant que es tractava de les dues opcions desitjables per a les dones de l'època, hi ha una gran coincidència en l'articulació organitzativa d'aquests dos 'ritus matrimonials'. Tot recorrent al terme del «teatre de la sociabilitat», considera Creixell que: «l'entrada en un convent d'una filla era un canvi d'estat igual d'important que si aquesta abandonés la solteria pel matrimoni carnal» (2012: 125) i, com aquest, també esdevenia motiu de celebració familiar i social. ${ }^{23} \mathrm{Amb}$ tot, evidentment, aquesta fastuositat ${ }^{24}$ només es donava quan es tractava de novícies amb un cognom il lustre, la família de la qual tenia mitjans suficients per fer-se càrrec de les despeses de la celebració i del convit amb familiars i amics (sovint personalitats importants). Aquest aparat llustrós buscava el lluïment social i, alhora, una fama en el nom de la futura religiosa que revertís també en el convent (Baranda 2011: 284). Es recorria llavors als músics professionals que s'encarregarien d'aquests textos musicats, molts dels quals van arribar a la impremta, costejats per les mateixes famílies, malgrat que ens resulten encara molt desconeguts. ${ }^{25}$

La interessant producció bibliogràfica que ha proliferat en els darrers anys, ha evidenciat la important contribució dels convents femenins al paisatge sonor de les ciutats a l'època moderna.

caputxines; Cusó (2009: 67) per al monestir de Vallbona de les Monges i Albacete \& Güell (2013: 123), per a les cistercenques de Valldonzella.

$22 \mathrm{Pel}$ que fa al teatre conventual, escrit i representat en l'esfera carmelitana femenina per a les ocasions, veg. Arenal \& Schlau (2010) i Borrego (2014). entre d'altres.

23 Creixell dóna compte de l'estructura i l'organització d'aquests rituals, tant del casament carnal com espiritual (2012: 125-133), amb dades molt més ampliades, recentment per a l'espai conventual femení de la Barcelona de 1700 (Creixell 2014). Sans i Travé ha estudiat la importància d'aquesta cerimònia per al monestir de santa Maria de Vallbona de les Monges (2010: 167-174).

24Malgrat que, tal com es lamenta la mateixa Rosa Creixell, la professió en una comunitat monàstica catalana no és un tema gaire tractat, ofereixen informació de primer ordre algunes fonts literàries com ara el dietari del baró de Maldà, on descriu la celebració d'una professió de la filla dels marquesos de Villel i comtes de Darnius. També sabem per M. Gras que l'arxiduquessa Isabel Cristina de Brunswick va assistir a Barcelona a la vestició (1710) i professió (1711) de Josepa de la Mare de Déu Feu i Falguera, filla de Pau Feu, destacat austriacista; els actes solemnes van comptar amb l'acompanyament musical de la capella reial (Gras 2013: 315, n. 16-17). També són d'obligada consulta els cerimonials de professió impresos, i conservats en algunes comunitats als quals tenim avui en dia accés de diverses plataformes, $\mathrm{i}$ que demostren com de variada podia ser la cerimònia en funció de l'ordre.

25 Tot amb tot, a l’àmbit catalanoparlant, més enllà de les valuoses aportacions de Baranda, manca encara per fer un catàleg d'aquest tipus de composicions. Trobem algunes notícies i títols en alguns treballs dedicats a la música religiosa i als mestres de capella d'època moderna així com catàlegs de biblioteques i en bases de dades com la de Manuscrits Catalans de l'Edat Moderna. Amb tot, és a través de la consulta directa dels catàlegs i inventaris de biblioteques públiques i universitàries (especialment útil és la consulta en línia del CCPBE) i arxius diversos, que accedim a aquesta producció dispersa i desconeguda. Per a la producció impresa generada al Carmel Descalç català, consulteu el Diccionari de Gras.

SCRIPTA, Revista internacional de literatura i cultura medieval i moderna, núm. 7 / juny 2016 / pp. 160-186 ISSN: 2340-4841 · doi:10.7203/SCRIPTA.7.8475 
Verònica Zaragoza Gómez. Poesia i cant per a la festa: revisió de les composicions creades amb motiu de vesticions i professions al convent de carmelites descalces de Barcelona (segle XVII).

Permet veure, a més, com l'execució musical va suposar a les comunitats una eina d'integració amb el seu entorn urbà, en la mesura que solien exercir de centres culturals on s'executava música i solien comptar amb l'assistència de personalitats importants de la societat i de la vida política. Sabem que els convents de monges, no només del Carmel sinó també d'altres ordes, van esdevenir centres musicals (juntament amb les grans seus catedralícies i esglésies), on la poesia cantada o musicada acomplia una funció de sociabilitat fonamental en les solemnitats conventuals, com podien ser les vesticions i professions solemnes, de les quals ens ocupem. Ho coneixem, per exemple, per al convent de Santa Maria de Jonqueres a Barcelona, de l'orde de Sant Jaume, d'unes característiques ben concretes; l'estudi abordat per Mazuela-Anguita 2015) demostra com les monges participaven en sepelis reials i com els convents es van convertir en imponents escenaris de festes amb música, especialment, en les cerimònies de professions ${ }^{26}$ a les quals podien assistir membres destacats de la noblesa:

\begin{abstract}
Sus entradas y profesiones en la misma época, hacíanse con grande ostentación, concurriendo deudos, padrinos, y las familias más distinguidas de la nobleza. Regularmente intervenía la capilla de música, y se adornaban los altares con multitud de flores y luces. Todos los asistentes llevaban sendas velas, la profesanda de á cuatro libras, la priora de una y las demás religiosas, clérigos y familiares de menos tamaño (cfr. Mazuela-Anguita 2015: 41).
\end{abstract}

Pel que fa a la composició i execució dels villancets paralitúrgics en les festes de professions solemnes a l'esfera monàstica femenina, l'estudiosa N. Baranda (2011) ha abordat recentment el tema en un primer estudi aproximatiu molt complet, que evidencia com d'heterogeni i complex és aquest camp de producció, que nosaltres només pretenem abordar en aquest primer treball aproximatiu, des de la producció del Carmel descalç català. Baranda proporciona interessants reflexions sobre la producció de plecs solts impresos a l'àmbit hispànic fins a 1749, a partir de l'anàlisi de 182 impresos (alguns creats per a convents femenins valencians i catalans). L'estudiosa hi analitza amb detall dates i llocs de producció, així com els elements constitutius del plec solt (aspectes formals, títol i la seva funcionalitat al si de les cerimònies conventuals) i els temes dels textos poètics resultants. En aquests impresos, normalment, al costat del nom de professa -i del convent-, hi havia anotat també el del director musical i de la capella de música que assumia la interpretació de la melodia, però en molt poques ocasions s'hi deixava constància de l'autor encarregat de compondre la lletra; ${ }^{27}$ fins al punt que Borrego (2012) ha explorat la qüestió de l'anonímia com a mecanisme d'ocultament d'identitat autorial en aquest subgènere. Siga com siga, l'estudi de Baranda verifica

26 Per a l'esmentat convent, sabem que assistien, fins i tot, els cavallers de l'Orde de sant Jaume: «En ese Monasterio, se juntan todos los caualleros del habito de Santiago, en ciertas jornadas, para celebrar sus fiestas, confessar y comulgar, vestidos con sus habitos, y capas blancas, con mucha deuuocion» (cfr. Mazuela-Anguita 2015: 40. n. 8).

27 «Casi todos los pliegos barceloneses y muchos de su área de influencia incluyen en la titulación el nombre de la capilla musical que canta en la cerimonia y el maestro que la dirigió [...] Los maestros se repite por períodos cronológicos y también las capillas, entre als cuales las del Palau y la de la catedral son las más citadas» (Baranda 2011: 281).

SCRIPTA, Revista internacional de literatura i cultura medieval i moderna, núm. 7 / juny 2016 / pp. 160-186 ISSN: 2340-4841 · doi:10.7203/SCRIPTA.7.8475 
Verònica Zaragoza Gómez. Poesia i cant per a la festa: revisió de les composicions creades amb motiu de vesticions i professions al convent de carmelites descalces de Barcelona (segle XVII).

que la impressió dels plecs solts de professió va ser un fenomen que es va donar a l'àmbit hispànic en unes coordenades geogràfiques ben concretes: generalment als convents aragonesos i catalans, amb centres a les ciutats de Saragossa i, especialment, Barcelona (Baranda 2011: 276-277). Per a l'àrea barcelonina, la preeminència del títol Villancicos que se cantaron i, en menor proporció, altres fórmules més elaborades (Epithalamio sacro.., ${ }^{28}$ Festivas y sacras consonancias en la profession y velo...) demostren que la impressió i la difusió del plec solt era posterior a la cerimònia (Baranda 2011: 281-283).

Les professions al Carmel Descalç, més enllà del ritual solemne que se celebrava a portes tancades al convent, també van motivar celebracions socials sonades, tal com podem documentar amb la realització d'un certamen, celebrat el 1660 al convent de carmelites de Santa Anna de València -i no conservat tret d'algunes poques peces que s'hi refereixen a la rúbrica-amb motiu de la professió de la noble Eugènia de Castro, que hauria reunit els lletrats de l'època. ${ }^{29}$

En d'altres ocasions i ordes religiosos, la manca de recursos condicionava la celebració de festes amb menys aparat i elements organitzatius i repercutia en unes cerimònies més íntimes, per bé que la poesia musicada també hi era present. En aquesta mena de festa se circumscriu la «Trova de la cantara $O$ cielos para cuando los rayos?») cantada per Teresa Ortí i Bonavida, de 9 anys, amb motiu de l'ingrés de la seva cosina Maria Lorenzo Bonavida i Tallada al convent d'agustines de Sant Cristòfor de València, el 12 de novembre de 1712 (cfr. Baranda 2011: 284-285). De fet, en aquest tipus de celebracions a cavall de l'àmbit públic i del privat, hi podem circumscriure també tres composicions anònimes, en castellà, que una dona va escriure a la professió de la seva íntima amiga Josefa Duran Rubio Tallada i Salinas (de nom religiós sor Teresa Josefa de Jesús) al convent de carmelites descalces de Sant Josep de València, el 25 d'octubre de 1753 (editades a Zaragoza 2016). ${ }^{30}$

\subsection{Les cerimònies d'ingrés en l'àmbit privat i íntim de la clausura}

Cal tenir present que aquests plecs impresos als quals ens estem referint només eren «un element addicional de boat celebratiu que donaria un relleu públic al que era de fet una cerimònia privada»

28Demostra clarament la vinculació de la professió religiosa al matrimoni amb Déu.

29 De la justa, però, només es conserven tres peces aportades per Llorenç Mateu i Sanç, d’acord amb el cartell del certamen. Les peces són una introducció a la justa, que va aportar-hi en qualitat de secretari, la segona un vexamen en forma de col loqui que van aportar germans Lluís i Isidor, i la tercera una enhorabona a la postulanta «en nombre de un niño», transcrites i estudiades per Mas i Usó (2009: 393-407).

30 En plec solt imprés dels villancets que es van cantar per celebrar aquesta professió, hi ha una peça amb la rúbrica: «Congratulase en la Profesion de Doña Josepha Duran, en la Religion Sor Teresa Josepha de Jesus, una intima Amiga suya, en este ENDECASYLABO», l'autoria de la qual atribuïm a alguna religiosa de la comunitat, que l'hauria escrit (?) per cantar-la en aquell moment festiu. A continuació hi trobem un sonet i unes seguidilles, que malgrat que no tenen cap marca d'autoria, considerem que podrien ser de la mateixa autora, ja que considerem que les rúbriques («Soneto») i («Siguidillas»), porten implícit la informació autorial present en la peça anterior (Mystico epithalamio: 14-16).

SCRIPTA, Revista internacional de literatura i cultura medieval i moderna, núm. 7 / juny 2016 / pp. 160-186 ISSN: 2340-4841 · doi:10.7203/SCRIPTA.7.8475 
Verònica Zaragoza Gómez. Poesia i cant per a la festa: revisió de les composicions creades amb motiu de vesticions i professions al convent de carmelites descalces de Barcelona (segle XVII).

(Gras 2013: 315); cerimònia que, òbviament, podia variar en funció dels ordes monàstics i, inclús, segons els convents. El cert és que, tal com es llegeix al cerimionial, bona part d'aquestes cerimònies se celebraven en la més absoluta intimitat, a l'interior de la clausura, davant l'única presència de les religioses i de l'autoritat eclesiàstica corresponent.

Òbviament, en el marc d'aquestes festes internes, hi podia haver també un espai important per a la improvisació, més enllà del que marcava estrictament el cerimonial, en què les religioses -no només de l'orde carmelità, malgrat que en tenim moltes notícies- acollien amb alegria les noves novícies amb cobles i villancets festius. Parlem de peces efímeres, sovint només de consum intern (a tot estirar podien circular entre convents del mateix orde) que, si s'han conservat (a causa del seu caràcter improvisat), ha estat per via manuscrita, gràcies al seu trasllat en cançoners col lectius. Pel que fa al panorama d'aquest tipus de producció referida a l'àmbit català, hem pogut documentar casos de religioses que cantaven cobles com a expressió de joia en el moment d'alguna professió, presa de vel o ingrés, no sempre conservades. A l'ambient carmelità, tenim exemples molt interessants de festes celebrades a l'interior dels convents en paral lel al que marcava el cerimonial i que implicaven la integració de la poesia amb la música i el cant. Ens el proporciona, p. exemple, el biògraf de Maria Alberta de Sant Domènec (Urús, 1657-Vic, 1739), gràcies al qual sabem que, quan aquesta va prendre l'hàbit al convent de carmelites descalces de Santa Teresa de Vic, el 1684, la priora li va demanar que cantés, en un moment de recreació després de la cerimònia:

\begin{abstract}
En la noche del mismo día después de aver salido la comunidad del refitorio, concedió la priora recreación por un rato a las religiosas, en expressión del contento y obsequio de la nueva hermana novicia. Y hecho algún religioso entretenimiento por las más recientes hermanas mandó la priora a la hermana Alberta que cantasse alguna canción, la qual desempeñó con gran gusto de la comunidad su obediencia, porque tenía la voz muy sonora, entera y galosa. Después dispuso que baylasse la misma nueva hermana y con modesto ayre se desempeñó también (Caralps 1747: 49).
\end{abstract}

A més, referit a un altre orde, la Vida de sor Josefa Nebot (Bocairent, 1750-1773), agustina virtuosa del convent de Nostra Senyora dels Dolors i dels Sants Reis de Bocairent (València), explica que, el mateix dia que la religiosa va arribar a la comunitat «cantaron las religiosas unos alegres motetes El esposo Jesús. Dijéronle a Josepha que cantara y, ésta sin aser melindre [excessos] alguno, se puso a cantar unas coplillas de Santa Rosa de Lima, donde a más de oír su voz, se vio el espíritu y fervor con que cantava» (Zaragoza 2016).

Com veiem, aquestes efemèrides d'entrada al convent van ser motiu d'inspiració d'una part important de la poesia conventual femenina a l'època moderna, per tal com es tractava d'un dels moments més importants de la vida d'una dona que aspirava a la vida religiosa i pretenia esborrar la seva identitat seglar. 
Verònica Zaragoza Gómez. Poesia i cant per a la festa: revisió de les composicions creades amb motiu de vesticions i professions al convent de carmelites descalces de Barcelona (segle XVII).

\section{La celebració poètica de vesticions i professions al convent de la Immaculada Concepció}

\section{de Barcelona: textos, temes i autoria}

Dit tot això, el Cançoner de carmelites descalces de Barcelona que hem pogut revisar i estudiar (Zaragoza [en premsa]), amb un total de 186 composicions, ${ }^{31}$ representa un testimoni d'excepció d'aquesta tradició poètica documentada a l'àmbit català, ja que la copista del moment es va encarregar de recopilar un total de vint-i-cinc peces (numerades fins a la 22, p. 156-171) que les religioses havien anat creant per ser cantades en aquest tipus de celebracions conventuals que comentem: al vel, a l'hàbit i a la professió solemne. En la majoria de les composicions s'hi revela el nom de la religiosa i el motiu pel qual foren escrits els versos, bé en la rúbrica o bé en la composició mateixa, adreçada normalment com una exhortació o invitació a la religiosa en 2a persona (amb tractament de 'vós'), el nom de la qual sol constar-hi en forma de vocatiu quan apareix entre versos. Per bé que algunes peces no ens diuen el nom a qui van adreçades, hem pogut contrastar algunes referències biogràfiques amb els registres del llibre de professions de la comunitat ${ }^{32}$ i constatem que les peces estan referides a vesticions i professions de principis del segle XVII, la qual cosa ens permet situar cronològicament aquesta producció i datar, almenys, l'escriptura (no la còpia) d'aquest cicle.

Tal com hem pogut avançar en un altre treball (Zaragoza (2016) i [en premsa]), l'autora identificada de la còpia d'aquesta sèrie poètica al cançoner col lectiu és Clara del Santíssim Sagrament Granllochs i Blanes, autora almenys d'una de les dues peces sobre desafiaments espirituals que ella mateixa recull intercalada en el cicle a vels i professions (p. 168-169), per tal com també proporcionen el camí de virtut a seguir. De nom seglar Clara Eugènia Granollacs i Blanes (Vic, 1591-Barcelona, 1648), pertanyia a la família promotora de la comunitat: fou filla de Miquel Granollacs -germà de Francesc de Granollacs, fundador del convent barceloní- i de la valenciana Àngela Granollacs i Blanes. A setze anys, va professar al convent de la Immaculada Concepció, on va exercir càrrecs importants: va ser-ne clavaria el 1627 i priora al llarg de tres triennis, durant 1630-1633, 1637-1640 i 1646-1648, any en què va morir. ${ }^{33}$ Dotada d'una cal ligrafia clara i ordenada, a ella es deu la transcripció de la majoria de les peces: un total de 79 composicions (el 42\% del quadern) que, en general, s'agrupen en tres cicles ben definits i delimitats, propis de la tradició lírica carmelitana (Orozco 1959; García de la Concha \& Álvarez 1982; Álvarez Pellitero 1983) i, emmarcats, en les celebracions conventuals privades: el cicle nadalenc, el cicle de les devocions conventuals (hagiogràfic i festivitats) i el cicle de vels, hàbits i professions que ens interessa ara. La dedicació poètica provada de la copista i el

31 Arxiu Convent Carmelites Descalces de Barcelona (en endavant, ACCDB), s. sign.

32 ACCDB Libro de la fundación y professión de las religiosas deste convento de nuestra Señora de la Concepción de carmelitas descalças de la ciudad de Barcelona. Malauradament, només podem documentar la data de professió i no la de vestició (que normalment era un any anterior) ja que el llibre conventual només conté dades de vestició a partir de 1633, mentre que hi ha registrades les dates de professió des de la mateixa fundació.

33 ACCDB, Libro de la fundación y professió..., p. 6. Llegiu Diccionari [s.v. Clara del Santíssim Sagrament, Granollacs Blanes (Vic, 1591-1648, Barcelona)].

SCRIPTA, Revista internacional de literatura i cultura medieval i moderna, núm. 7 / juny 2016 / pp. 160-186 ISSN: 2340-4841 · doi:10.7203/SCRIPTA.7.8475 
Verònica Zaragoza Gómez. Poesia i cant per a la festa: revisió de les composicions creades amb motiu de vesticions i professions al convent de carmelites descalces de Barcelona (segle XVII).

caràcter de les peces que transcriu ens podria fer atribuir peces del cicle que comentem a sor Clara del Santíssim Sagrament, però, òbviament, no tenim dades per verificar-ho de moment.

Aquesta sèrie poètica o cicle del manuscrit poètic carmelità barceloní, s’inicia amb dues peces cantades a l'hàbit i al vel d'Arcàngela de l'Encarnació ${ }^{34}$, que va professar a la comunitat el 30 de juliol de 1603: «1 $1^{\mathrm{a}} \mathrm{Al}$ abito dela hermana arcangela coplas». Inc.: «Seais, Arcángela, bienvenida....» (p. 156) i «Otras al velo». Inc.: «Para siempre le gocéis...» (p. 156). ${ }^{35}$ A continuació, trobem unes cobles a l'hàbit de Magdalena de Jesús, ${ }^{36}$ que va rebre la professió el 30 de novembre de 1603: «2a coplas al abito de la her $^{\text {na }}$ madalena de jesus». Inc.: «Muy bien vengáis, Madalena...» (p. 157-158).

La mateixa copista Clara del Santíssim Sagrament es va preocupar de recopilar cinc peces escrites per a celebrar la seva professió, el 25 de setembre de 1607, juntament amb les de la vestició prèvia: «3a coplas al abito de la her ${ }^{\text {na }}$ clara del Smo Sacrameto». Inc.: «Más que el sol lindo y hermoso...» (p. 158); «Otras. 4a». Inc.: «Clara, el niño Jesús...» (p. 158-159); «A la profesion de la her ${ }^{\text {na }}$ clara del $\mathrm{s}^{\mathrm{mo}}$ sacramento 14». Inc.: «Pues que quedáis desposada...» (p. 166); «Otras». Inc.: «Pues del grande Emanuel...» (p. 166); «Otras. 15a». Inc.: «Pues que ya sois, Clara...» (p. 167); «Otras para el velo». Inc.: «Pues que, Clara, sois velada...», p. 167.

Hi trobem, a més, unes cobles a l'hàbit de Jerònima de Jesús Maria ${ }^{37}$, que hi va rebre la professió l'1 de maig de 1605: «Otras al abito de la hermana geronima de jesus maria. 5a». Inc.: «Bien parece que Jesús...» (p. 159-160).

Hi segueixen cinc peces dedicades a la vestició i professió de Teresa de Jesús, ${ }^{38}$ que hi va professar el 20 d'agost de 1608: «Coplas al abito de la her ${ }^{\text {na }}$ teresa de jesus. 6a». Inc.: «Teresa, siempre gocéis...» (p. 160); «Otras. 7a». Inc.: «Pues que el reinar...» (p. 160-161); «Otras. 8a». Inc.: «¿Qué buscáis, mansa

34 Arcàngela de Menargues i Fernàndez (Tàrrega, 1566-Barcelona, 1628), fou filla de Tomàs Joaquim de Menargues, i d'Anna de Menargues i Fernàndez (ACCDB, Libro de la fundación y professión..., p. 4).

35 Aquesta no duu el nom de la novícia i va sense numeració, però podríem atribuir-la al vel de la mateixa, si considerem que hi ha una voluntat d'ordenació de les poesies per part de la copista.

36 Magdalena de Jesús Campllonc (Barcelona, 1572-1613), fou filla de Bernat Campllonc, i de Caterina Campllonc (ACCDB, Libro de la fundación y professión..., p. 4).

37 Jerònima de Jesús Maria Fontana Fabregat, (Barcelona, 1588-1626) fou filla de Jeroni Fontana, notari reial, i d'Aldonça Fabregat (ACCDB, Libro de la fundación y professión..., p. 5).

38 Teresa de Jesús Meca Vilana (Vergós, 1592-Barcelona, 1636), fou filla d’Antoni Meca, i de Mariana Meca i Vilana, senyors de Vergós (ACCDB, Libro de la fundación y professión..., p. 7). 
Verònica Zaragoza Gómez. Poesia i cant per a la festa: revisió de les composicions creades amb motiu de vesticions i professions al convent de carmelites descalces de Barcelona (segle XVII).

cordera,...», (p. 161); ${ }^{39}$ "A la profesion de la her ${ }^{\text {na }}$ teresa de jesus coplas 16». Inc.: «Bendecid siempre al Señor...» (p. 167-168); «Al velo de la her ${ }^{\text {na }}$ teresa de Jesus coplas 19». Inc.: «El artífice del cielo...» (p. 169-170).

Un grup de set composicions està dedicat a la vestició i professió d'Isabel de la Mare de Déu ${ }^{40}$, que va professar l'1 de maig de 1605: «Otras al abito de la her ${ }^{\text {na }}$ ysabel. 9a». Inc.: «¿Qué buscáis, decid, Isabel...?» (p. 161-162); «Coplas a la profesion de la her ${ }^{\text {na }}$ 10a». Inc.: «Pues con Cristo desposada...» (p. 162-163); «Otras. 11a». Inc.: «Pues que sois de Dios esposa...» (p. 163); «Al velo. Coplas 12a». Inc.: «Pues, hermana, tan hermosa...» (163-164); «13 Ala profesion de la her ${ }^{\text {na }}$ ysabel de la $m^{\text {e }}$ de dios». Inc.: «Hoy a muertos han tañido...» (p. 164-165); «Otras». Inc.: «Dichome han Isabel...» (p. 165); «Al velo de la misma». Inc.: «Velo os ponen, Isabel...» (p. 165).

Finalment, el Cançoner recull una composició per a la vestició de Caterina de Crist, que va professar el 9 de maig de 1619:41 «coplas al abito de la her ${ }^{\text {na }}$ catalina de xpo 20». Inc.: «Hoy la majestad divina...» (p. 170-171) i una altra peça que tanca la sèrie, de la qual, malauradament, només van ser copiats els quatre primers versos, que ens permeten saber que anava dedicada a la mateixa religiosa: «22 Al ponerle la corona». Inc.: «La corona os dan con gozo...» (p. 171).

Sobre l'estructura mètrica de les composicions del cicle, totes segueixen la forma de villancet, ${ }^{42} \mathrm{amb}$ una estrofa que funciona d'introducció i que reporta els versos que després es repeteixen en les cobles (coplas) que la glossen o en repeteixen el contingut. Ho veiem a mode d'exemple en la primera peça de la sèrie copiada al manuscrit, consagrada a la presa d'hàbit Arcàngela de l'Encarnació de Menargues i Fernàndez:

\title{
$1^{\mathrm{a}} \mathrm{Al}$ ábito dela hermana Arcángela. Coplas
}

Seáis, Arcángela, bienvenida

a gozar la religión.

Dios os dé su bendición

\begin{abstract}
39 Suposem que aquesta peça també va dedicada a la professa de les dues peces anteriors perquè va a continuació d'aquestes; tanmateix, no ho podem provar del tot perquè no duu cap informació al respecte.

40 Isabel de la Mare de Déu Albanell Soler (Barcelona, 1565-1640), fou filla d’Enric Albanell, i d’Àngela Albanell i Soler (ACCDB, Libro de la fundación y professión..., p. 5).

41 De nom seglar Lluïsa de Granollacs de Forcià (Avinyó, França?, Barcelona, 1665), fou filla de Joan Granollacs, i de Francesca Granollacs i Forcià. Va professar el 9 de maig de 1619 (ACCDB, Libro de la fundación y professió..., p. 8).

42 En aquest aspecte, hem de tenir-hi present la gran diversitat estructural i formal del villancet, tal com es va veure en la necessitat de remarcar Josep Vicens, el 1703, en la seva revisió del Arte poética, de Juan Díaz Rengifo: «Después de las reglas en común para los villancicos, parece muy del caso advertir algunas singularidades, que puedan abrir camino: para esto se presupone que constan los villancicos, algunos de introducción, estribillo y coplas; otros de solo estribillo y coplas; otros de introducción, estribillo y recitativo; otros de estribillo y recitativo; otros de recitativo solo; y otros de coplas solas» ([1759]: 52-53).
\end{abstract}


Verònica Zaragoza Gómez. Poesia i cant per a la festa: revisió de les composicions creades amb motiu de vesticions i professions al convent de carmelites descalces de Barcelona (segle XVII).

4

8 $y$ después la eterna vida.

Seáis Arcángela, bien llegada, al paraíso dichoso que en la tierra vuestro Esposo os tiene como su amada; vivid en él transformada sin cansaros noche y día. Dios os dé su bendición $y$ después la eterna vida.

Vuestra vida ha de ser ir siempre tras el cordero con un amor verdadero para más le poseer hasta que le podáis ver en la patria prometida. Dios os dé su bendición $y$ después la eterna vida.

(p. 156)

Entre aquestes peces, amb estructura i to coincidents, en trobem d'altres que reprodueixen dues veus poètiques, possiblement per a ser cantades per la postulant i per altres religioses; recurs freqüent en el panorama de versos cantats per a preses de vel estudiat per Llergo (2016). Com veiem en la peça que copiem a continuació, en algunes d'aquestes peces, s'hi teatralitza el ritual de cerimònia ${ }^{43}$ a través d'una estructura pregunta-resposta ${ }^{44}$ que implicaria la resposta de la mateixa postulant:

Otras. 21a

P. «¿Qué buscáis con tal contento, aquí en esta soledad?».

4

R. «Al que es mi gloria y mi sentro,

el Dios de la majestad».

«Mirad que us ha de costar

diciplinas y silisios

y otros mil ejersicios

8

para podelle topar».

43 Recordem que en la cerimònies d'ingrés i professió, l'aspirant a la vida religiosa havia de respondre un qüestionari, seguint un ritual ja estipulat.

44 Altres peces de la sèrie també segueixen aquesta estructura, en què la veu de la professa apareix responent les demandes de les seves companyes, emissores del discurs.

SCRIPTA, Revista internacional de literatura i cultura medieval i moderna, núm. 7 / juny 2016 / pp. 160-186 ISSN: 2340-4841 · doi:10.7203/SCRIPTA.7.8475 
Verònica Zaragoza Gómez. Poesia i cant per a la festa: revisió de les composicions creades amb motiu de vesticions i professions al convent de carmelites descalces de Barcelona (segle XVII).

R. «Todo lo podré llevar confiada en su piedad para hallar mi gloria y sentro, el Rey de la majestad》.

«Descalsa habréis de andar, de toda afisión del suelo que en este santo Carmelo

16 tal calsado no ha de entrar». R. «Eso y más vengo a buscar movida de su bondad del ques mi gloria y mi sentro, el Rey de la majestad».

«También habéis de dejar en todo vuestro consuelo no queriendo acá en el suelo sino por Cristo penar».

R. «Solo a Él le quiero amar y seguir con humildad, pues es mi gloria y mi sentro, el Rey de la majestad».

(p. 171)

En altres casos, la resposta de la religiosa, davant les d'una altra veu poètica (o d'altres) apareix repetida en la tornada final que tanca cada estrofa:

Otras alabito de la hermana Ysabel $9^{\mathrm{a}}$.

«¿Que buscáis decid, Isabel?

Dadnos dello clara luz».

«Vengo a buscar a Jesús

4 por morir en cruz con Él».

«Si venís para morir dichosa es vuestra venida, pues en Cristo vuestra vida

8 escondéis por más vivir, si en él siempre convertir os procuráis, Isabel». «Vengo a buscar a Jesús por morir en cruz con Él».

«Vuestra muerte ha de ser para todo lo criado, sin quedaros reservado 
Verònica Zaragoza Gómez. Poesia i cant per a la festa: revisió de les composicions creades amb motiu de vesticions i professions al convent de carmelites descalces de Barcelona (segle XVII).

16

32

36 tilde de propio querer porque así más poseer podáis a Dios, Isabel». «Vengo a buscar al amado por morir en cruz con Él».

«Y guardad vuestra afición de todo cuanto hay criado que el demonio disfrazado os querrá hacer traición, diciendo que es perfición lo que no lo es, Isabel». «Vengo a buscar al amado por morir en cruz con Él»».

«Solo os procurad de asir de Cristo crucificado, y el corazón transformado le daréis por más le herir, para que siempre vivir quiera en vos y vos en él». «Vengo a buscar a Jesús por morir en cruz con Él».

(p. 161-162)

Sobre el tema que tracten, s'han de perfilar en el seu conjunt mitjançant nous treballs, però, en general, la veu poètica s'adreça a les postulants o novícies que han de rebre el vel, l'hàbit o la professió, per marcar-los el grau de perfecció que hauran d'assolir després del que es representa íntimament en les cerimònies ritualitzades, motiu de cant dels versos. Els motius i tòpics sobre els quals es basteix la poesia de professió ja estudiada són clarament identificables com a comunes en gairebé totes les peces de la sèrie: el tòpic del contemptus mundi, la mort o renúncia al món mundà («Hoy a muertos han tañido») i el combat de les seves passions («su vil escoria») per gaudir d'aquell «paraíso dichoso» o «desierto» que representa la nova vida eremítica i d'oració; la transformació i el goig en l'Espòs a través del matrimoni místic (procedent de la tradició literària del Càntic dels Càntics: «Pues prometiste de amar /a Cristo, que os ha ya entrado / en su tálamo sagrado»), el camí de perfecció a través del compliment d'una sèrie de virtuts religioses (obediència, caritat, humilitat, paciència...) i l'oració perpètua; la recerca de la soledat i la dolça esclavitud del nou estat... (García de la Concha 1976: 121 124; Llengo 2016). Ho llegim, per exemple, en aquesta altra peça a la presa de vel: 
Verònica Zaragoza Gómez. Poesia i cant per a la festa: revisió de les composicions creades amb motiu de vesticions i professions al convent de carmelites descalces de Barcelona (segle XVII).

\section{Otras al velo}

4

8

12

16

28
Para siempre le gocéis, esposa de vuestro Esposo, con el velo misterioso que en la cabeza traéis.

Advertid que habéis de estar para el mundo siempre muerta, solo para Dios despierta por poderle más amar hasta en él os transformar; noche y día no paréis pues velo tan misterioso en la cabeza traéis.

Procurad de ser trasumpto de obediencia y humildad y en perfeta caridad, sin que jamás perdáis punto, $\mathrm{y}$ aunque el mundo todo junto os persiga, no us quejéis pues velo tan misterioso en la cabeza traéis.

En perpetua oración pasaréis la noche y día, porque ella os será guía hasta el monte de Sión, adonde la posesión del amado alcanzaréis, pues velo tan misterioso en la cabeza traéis.

(p. 156)

\section{Conclusions}

Després del que hem apuntat en la primera part del treball, és fàcilment acceptable assumir que molts dels versos que ens han arribat de la tradició poètica carmelitana (i del convent de carmelites de Barcelona, en concret), s'emmarquen en el cicle festiu de les comunitats, amb motiu del qual les religioses creaven peces ex profeso o cantaven el repertori de cobles conservat per la tradició. Una tradició que tenim ben present en el llibre de costums santes de la comunitat de la Immaculada Concepció de Barcelona que, en referir-se a las «coplas tan fervorosas de nuestras Madres antiguas» invoca una tradició oral que es va convertir en tradició escrita, en el moment que les peces van ser copiades al manuscrit que hem estudiat, per a una millor memorització i per al record. I és 
Verònica Zaragoza Gómez. Poesia i cant per a la festa: revisió de les composicions creades amb motiu de vesticions i professions al convent de carmelites descalces de Barcelona (segle XVII).

que cal tenir present que bona part de les peces de la tradició carmelitana en general, van tenir un naixement eminentment oral (la qual cosa denota la seva simplicitat i caire repetitiu) i van ser usades com a càntics, presents en funcions de la vida quotidiana al claustre; susceptibles, per tant, no tan sols de l'oblit, sinó de modificacions sense importar-ne la procedència ni originalitat, ${ }^{45}$ fins que els textos es van acabar fixant per passar així a formar part del corpus poètic col lectiu. Per aquest motiu, és tan difícil atribuir l'autoria de la poesia d'aquests cançoners, pretesament anònims.

Gràcies al cançoner de les carmelites descalces de Barcelona hem pogut accedir a un dels cicles més importants de la tradició poètica religiosa, que respon a un dels subgèneres de més tradició en l'escriptura de poesia de monges: els versos dedicats a vels, hàbits i professions solemnes, creats per a ser cantats en aquestes festes d'ingrés de nous membres. Aquesta producció ha estat estudiada per a l’àmbit hispànic (amb la dedicació de les plomes més il lustres com la mateixa Teresa de Jesús), però rarament havia estat tractada en relació als testimonis de l'àmbit català. Per aquest motiu, en aquest article, hem analitzat a vastament el context català on s'origina aquesta producció i hem intentat aportar llum sobre una producció diversa i heterogènia que sabem que va eixir, en gran mesura, de la ploma de les mateixes religioses, emmarcada en les festivitats de la comunitat. Tot $\mathrm{i}$ que ens hem limitat a presentar aquest corpus poètic, creiem que és fonamental seguir-hi treballar, ampliant l'estudi a les peces que, sobre aquesta tipologia, també transmeten els manuscrits del convent de carmelites descalces Vic, com demostra l'estudi de Pessarrodona en aquest mateix monogràfic. Nous treballs i mirades ens permetran seguir penetrant en l'entramat cultural de les carmelites descalces a l'àmbit català durant els segles XVI-XVIII i relacionar els usos poètics, musicals i dramàtics amb les experiències de vida que ens han deixat les plomes d'aquestes dones del passat.

45 De fet, Orozco considera que aquesta apropiació i refosa dels versos d’altri als convents era «una forma más en la vida de una composición» (1959: 156). 
Verònica Zaragoza Gómez. Poesia i cant per a la festa: revisió de les composicions creades amb motiu de vesticions i professions al convent de carmelites descalces de Barcelona (segle XVII).

\section{Bibliografia}

Alarcón $\mathrm{M}^{\mathrm{a}}$ Carmen (2000) «Tras las huellas de Sor Marcela: Sor Francisca de Santa Teresa y el teatro conventual femenino del siglo XVII», dins L. García (ed.), Autoras y actrices en la historia del teatro español, Múrcia, Universidad de Murcia, 255-266.

- (2004) «El teatro en los conventos femeninos de Sevilla durante el Siglo de Oro: un festejo cómico de 1678», dins F. Domínguez \& M.L. Lobato (coord.), Memoria de la palabra: Actas del VI Congreso de la Asociación Internacional Siglo de Oro, vol. I, Madrid/Frankfurt: Iberoamericana/ Vervuert, 183-192.

Albacete, Antonio \& Güell, Margarida (2013) El reial monestir de Santa Maria de Valldonzella (1147-1922). Història $i$ art en un centre $d \square$ espiritualitat cistercenca, Barcelona, PAM (Biblioteca Abat Oliba, 290).

Álvarez, Anna M. (1983) «Cancionero del Carmelo de Medina del Campo (1604-1622)», en Teófanes Egido, Víctor García de la Concha \& Olegario González (ed.), Actas del Congreso Internacional Teresiano: 4-7 de octubre de 1982, vol. II, Salamanca, Universidad Salamanca, 525-543.

Arenal, Electa \& Schlau, Stacey (2010) Untold Sisters. Hispanic Nuns in Their Own Works, Albuquerque, University of New Mexico Press.

Baranda, Nieves (2011) «Cantos al sacro epitalamio o sea pliegos poéticos para las tomas de velo: deslindes preliminares», Bulletin Hispanique, 113/1, 269-296.

. (2013) «Producción y consumo poéticos en los conventos femeninos», Bulletin Hispanique, 115 $/ 1,165-184$.

Baranda, Nieves \& Marín, M. Carmen (ed. 2014): Letras en la celda. Cultura escrita de los conventos femeninos en la Espana moderna, Madrid / Frankfurt, Iberoamericana / Vervuert (Tiempo Emulado. Historia de América y España, 32).

Borrego, Esther (2012) «Los autores de las letras de los villancicos de la Capilla Real de Madrid (siglo XVII), ¿anonimia como costumbre u ocultamiento de identidades?», Revista de Musicología, $35 / 2,97-128$.

. (2014) «De la lírica a la escena: tres fiestas teatrales en el convento vallisoletano de la Concepción del Carmen (1600-1643)», Revista de Escritoras Ibéricas, 2, 11-40.

Caralps, M. (1747) Vida de la sierva de Dios, soror María Alberta de Sto. Domingo, carmelita descalca en el convento de Jesús, Maria, Joseph y Teresa de la ciudad de Vich, Vic, Pere Morera.

Creixell, Rosa M. (2012) «Espais interiors i parament domèstic», dins Interiors domèstics: Barcelona 1700, Barcelona, Ajuntament de Barcelona. Institut de Cultura (Ciutat del Born. Barcelona 1700, 8), 100-139.

(2014) «La Barcelona monàstica. La dona en la clausura», dins Les dones. Barcelona 1700, Barcelona: Ajuntament de Barcelona. Institut de Cultura (Ciutat del Born. Barcelona 1700, 11), 200-231.

Cusó, Marta (2009) Un monestir cistercenc femení català durant el primer segle borbònic espanyol. Santa Maria de Vallbona (1701-1802), Tesi doctoral, Universitat Autònoma de Barcelona [en línia: http://www.tdx. cat/handle/10803/4817] [consulta: 11/04/2016]. 
Verònica Zaragoza Gómez. Poesia i cant per a la festa: revisió de les composicions creades amb motiu de vesticions i professions al convent de carmelites descalces de Barcelona (segle XVII).

Díaz Rengifo, J. [1759]: Arte poética española: con una fertilíssima sylva de consonantes comunes, propios, esdrúxulo, y reflexos, y un divino estímulo del amor de Dios [...] aumentada en esta uiltima impressión con dos tratados, uno de avisos y reglas, otro de asonantes, Barcelona, Maria Àngela Martí, víuda.

Emeterio de Jesús María O.C.D. (1949) «Ensayo sobre la lírica carmelitana hasta el siglo XX», El Monte Carmelo, LIV, 5-176.

García de la Concha, Víctor (1970) «Conciencia estética y voluntad de estilo en San Juan de la Cruz», Boletín de la Biblioteca de Menéndez Pelayo, XLVI, 371-408.

- - (1976) «Tradición y creación poética en un carmelo castellano del Siglo de Oro», Boletín de la Biblioteca de Menénder Pelayo, LII, 101-133.

- (1977) El arte literario de Santa Teresa, Barcelona, Ariel.

García de la Concha, Víctor \& Álvarez Pellitero, Ana Ma (1982) Libro de Romances y Coplas del Carmelo de Valladolid (c. 1590-1606). 2 vol., Salamanca, Consejo General de Castilla y León. Servicio de Publicaciones.

Gras, M. Mercè (2013), «L'escriptura en el Carmel descalç femení: la província de Sant Josep de Catalunya (1588-1835)», Scripta: revista internacional de literatura i cultura medieval i moderna, 1, 302-332.

- (Diccionari) Diccionari biogräfic d'autors carmelites descalcos de laprovincia de Sant Josep [en línea: http://mcem.iec.cat/entrada.asp?epigraf $m=8$ ] [consulta: 09/4/2016]

Hanna, Daniel (2015) «Pour la fête de notre séraphique mère sainte Thérèse: A Teresian Celebration in Verse, and a Concise View of French Carmelite Poetry», Scripta: revista internacional de literatura $i$ cultura medieval $i$ moderna, 6, 2015, 166-175.

Herpoel, Sonja (2013) «Sociabilidad y literatura en los conventos femeninos del Siglo de Oro», dins Albert Mechthild (ed.), Sociabilidad y literatura en el Siglo de Oro, Frankfurt / Madrid, Vervuert / Iberoamericana (Biblioteca Aurea Hispánica, 84), 2013, 239-253.

Llergo, Eva (2016) «Composiciones poéticas para profesiones religiosas de santa Teresa de Jesús y otras carmelitas contemporáneas», eHumanista, 32, 113-125.

Manero, María Pilar (1991) «Ana de Jesús vista por Henri Bremond: un caso de comprensible incomprensión», Scriptura, 6-7, 25-40.

Mas i Usó, Pasqual (2009) Justas valencianas barrocas, València, Biblioteca Valenciana.

Mazuela-Anguita. Ascensión (2015) «La Vida musical en el Monasterio de Santa Maria de Jonqueres en los siglos XVI y XVII: Agraïda y Eugènia Grimau», Revista Catalana de Musicologia, VIII, 37-79.

Morujão, Isabel (2013) Por Tras da Grade - Poesia Conventual Feminina em Portugal (Seculos XVI-XVIII), Lisboa, Imprensa Nacional-Casa a Moeda.

Mystico: Mýstico epithalamio, cántico nupcial armonioso, en el feliz, bymeneo en el desposorio sagrado de una castíssima Sunamitis con el divino Salomón [...] Siendo en el siglo Doña Josepha Duran, Rubio, Tallada y Salinas, en la 
Verònica Zaragoza Gómez. Poesia i cant per a la festa: revisió de les composicions creades amb motiu de vesticions i professions al convent de carmelites descalces de Barcelona (segle XVII).

religión la Mad.e Teresa Josepha de Jesús. En el religiosíssimo y observantíssimo convento de Carmelitas Descalzas de San Joseph de la Ciudad de Valencia. Puesto en Musica por D. Fabián Llázer, arpista de la Metropolitana. Dia 25 de octubre del Año de 1753, València, vídua d'Antonio Bordàzar, [s.a.].

Orozco, Emilio (1959) Poesía y mística. Introducción a la lírica de san Juan de la Cruz, Madrid, Guadarrama.

- (1981) «Poesía devocional y festiva para cantos devocionales», dins Expresión, comunicación y estilo en la obra de Santa Teresa, Granada, Diputación Provincial, 153- 77.

(1987) Expresión, comunicación y estilo en la obra de Santa Teresa Granada, Excma. Diputación Provincial de Granada.

Ruiz, Pedro (1990) «Santa Teresa de Jesús: pragmática y poética», dins M. J. Mancho Duque (ed.), La espiritualidad del siglo ХИ: aspectos literarios y lingüisticos, Salamanca, Universidad de Salamanca, 185-191.

Sánchez, Milagros (1993) «Las recreaciones en el Carmelo: Ana de San Bartolomé. Análisis de una "conferencia espiritual"», dins M. García (ed.), Estado actual de los estudios sobre el Siglo de Oro: actas del II Congreso Internacional de Hispanistas del Siglo de Oro, vol. II, Salamanca: Universidad de Salamanca, 931-940.

Sans i Travé, J.M. (2010) El Monestir de Santa Maria de Vallbona. Història, Monaquisme i Art, Lleida, Pagès Editors.

Serra de Manresa, V. (2002) Les Clarisses-Caputxines a Catalunya i Mallorca: de la fundació a la guerra civil (1599-1939), Barcelona, Facultat de Teologia de Catalunya.

Silverio de Santa Teresa (1935) Historia del Carmen Descalzo en España, Portugal y América, vol. II, Burgos, [El Monte Carmelo].

Téllez González, Marina (2013) El coro bajo del Convento de San José: Espacio de la ritualidad femenina en el siglo XVII, Tesi de Llicenciatura, Mèxic, UNAM / FFyL / Colegio de Historia [en línia: http://132.248.9.195/ptd2013/mayo/408048035/Index.html] [consulta: 10/04/2016].

Zafra, Rafael (2015) «Las coplas descalzas: música y poesía en santa Teresa y sus carmelitas» Scripta theologica: revista de la Facultad de Teología de la Universidad de Navarra, 47 / 3, 735-759

Zaragoza, Verònica (2016), «En vers vull desafiar...». La poesia femenina a l'àmbit català (segles ХИI-ХИIII), Edició crítica, 2 vol., Tesi Doctoral inèdita. Universitat de Girona.

- - [en premsa] «Cantalde a uso de corte un villancico galán’. Primera aproximación al Cancionero poético del convento de carmelitas descalzas de Barcelona (c. 1588-1805)», Relaciones. Estudios de historia y sociedad. El Colegio de Michoacán. 
Verònica Zaragoza Gómez. Poesia i cant per a la festa: revisió de les composicions creades amb motiu de vesticions i professions al convent de carmelites descalces de Barcelona (segle XVII).

\section{Annex: Cicle d'hàbits i professions al Cançoner de carmelites descalces de Barcelona (p. 156-171) $)^{1}$}

\begin{tabular}{|c|c|c|c|c|}
\hline [1] & $\begin{array}{l}\text { «1 } 1^{\mathrm{A}} \mathrm{Al} \text { abito dela } \\
\text { hermana arcangela } \\
\text { coplas». }\end{array}$ & $\begin{array}{l}\text { Inc.: «Seay arcangela } \\
\text { bienvenida...» }\end{array}$ & p. 156 & $\begin{array}{l}\text { [1] Hàbit d'Arcàngela de } \\
\text { l'Encarnació }\end{array}$ \\
\hline [2] & «Otras al velo» & Inc.: «Para siempre le goceis...» & p. 156 & $\begin{array}{l}\text { Vel d'Arcàngela de } \\
\text { l'Encarnació (?) [s.n] }\end{array}$ \\
\hline [3] & $\begin{array}{l}\text { «2a coplas al } \\
\text { abito de la her }{ }^{\text {na }} \\
\text { madalena de } \\
\text { jesus». }\end{array}$ & $\begin{array}{l}\text { Inc.: «mui bien vengais } \\
\text { madalena...» }\end{array}$ & pp. $157-158$ & $\begin{array}{l}\text { [2] Hàbit de Magdalena de } \\
\text { Jesús }\end{array}$ \\
\hline [4] & $\begin{array}{l}\text { «3a coplas al abito } \\
\text { de la her }{ }^{\text {na }} \text { clara del } \\
\mathrm{S}^{\text {mo }} \text { Sacrameto» }\end{array}$ & $\begin{array}{l}\text { Inc:: «Mas quel sol lindo y } \\
\text { hermoso...» }\end{array}$ & p. 158 & $\begin{array}{l}\text { [3] Hàbit de Clara del } \\
\text { Santíssim Sagrament }\end{array}$ \\
\hline [5] & «Otras. 4a» & Inc:: «clara el niño jesus...». & pp. 158-159 & $\begin{array}{l}\text { [4] Sense referència. Clara } \\
\text { del Santíssim Sagrament }\end{array}$ \\
\hline [6] & $\begin{array}{l}\text { «Otras al abito } \\
\text { de la hermana } \\
\text { geronima de jesus } \\
\text { maria. 5a» }\end{array}$ & Inc.: «bien paresce que jesus...» & pp. $159-160$ & $\begin{array}{l}\text { [5] Hàbit de Jerònima de } \\
\text { Jesús Maria }\end{array}$ \\
\hline [7] & $\begin{array}{l}\text { «Coplas al abito de } \\
\text { la her }{ }^{\text {na }} \text { teresa de } \\
\text { jesus. 6a» }\end{array}$ & Inc.: «Teresa siempre goseis...» & p. 160 & $\begin{array}{l}\text { [6] Hàbit de Clara del } \\
\text { Santíssim Sagrament } \\
\text { Granollacs }\end{array}$ \\
\hline [8] & «Otras. 7a» & Inc.: «Pues que el reynar...» & pp. 160-161 & $\begin{array}{l}\text { [7] Sense referència. Teresa } \\
\text { de Jesús Meca Vilana }\end{array}$ \\
\hline [9] & «Otras. 8a» & $\begin{array}{l}\text { Inc.: «que buscais mansa } \\
\text { cordera...» }\end{array}$ & p. 161 & $\begin{array}{l}\text { [8] Sense referència. Teresa } \\
\text { de Jesús Meca Vilana (?) [s.n] }\end{array}$ \\
\hline [10] & $\begin{array}{l}\text { «Otras al abito de } \\
\text { la her }{ }^{\text {na }} \text { ysabel. 9a» }\end{array}$ & $\begin{array}{l}\text { Inc:: «Que buscais deci } \\
\text { ysabel...» }\end{array}$ & pp. $161-162$ & $\begin{array}{l}\text { [9] Hàbit d'Isabel de la Mare } \\
\text { de Déu }\end{array}$ \\
\hline [11] & $\begin{array}{l}\text { «Coplas a la } \\
\text { profesion de la } \\
\text { her }^{\text {na }} 10 \mathrm{a} »\end{array}$ & $\begin{array}{l}\text { Inc:: «Pues con cristo } \\
\text { desposada...» }\end{array}$ & pp. 162-163 & $\begin{array}{l}\text { [10] Professió d'Isabel de la } \\
\text { Mare de Déu [s.n] }\end{array}$ \\
\hline [12] & «Otras. 11a» & $\begin{array}{l}\text { Inc.: «Pues que sois de dios } \\
\text { esposa...» }\end{array}$ & p. 163 & $\begin{array}{l}\text { [11] Sense referència. Isabel } \\
\text { de la Mare de Déu (?) [s.n] }\end{array}$ \\
\hline [13] & $\begin{array}{l}\text { «Al velo. Coplas } \\
12 \mathrm{a} »\end{array}$ & $\begin{array}{l}\text { Inc:: «Pues hermana tan } \\
\text { hermosa...» }\end{array}$ & pp. 163-164 & $\begin{array}{l}\text { [12] Al vel d'Isabel de la } \\
\text { Mare de Déu (?) [s.n] }\end{array}$ \\
\hline [14] & $\begin{array}{l}\text { «13 Ala profesion } \\
\text { de la her }{ }^{\text {na }} \text { ysabel } \\
\text { de la } \mathrm{m}^{\mathrm{e}} \text { de dios» }\end{array}$ & $\begin{array}{l}\text { Inc.: «Oy a muertos an } \\
\text { tañido...» }\end{array}$ & pp. $164-165$ & $\begin{array}{l}\text { [13] A la professió d’Isabel } \\
\text { de la Mare de Déu }\end{array}$ \\
\hline
\end{tabular}

1 [s.n]: sense menició al nom de la religiosa a qui va adreçada; [sense referència]: sense menció a l'ocasió de poetització (hàbit, professió o vel). 
Verònica Zaragoza Gómez. Poesia i cant per a la festa: revisió de les composicions creades amb motiu de vesticions i professions al convent de carmelites descalces de Barcelona (segle XVII).

\begin{tabular}{|c|c|c|c|c|}
\hline [15] & «Otras» & Inc.: «dicho me an hisabel...» & p. 165 & $\begin{array}{l}\text { Sense referència. Isabel de la } \\
\text { Mare de Déu }\end{array}$ \\
\hline [16] & $\begin{array}{l}\text { «Al velo de la } \\
\text { misma» }\end{array}$ & Inc:: «Velo os ponen ysabel» & p. 165 & $\begin{array}{l}\text { Al vel d'Isabel de la Mare } \\
\text { de Déu }\end{array}$ \\
\hline [17] & $\begin{array}{l}\text { «A la profesion de } \\
\text { la her }{ }^{\text {na }} \text { clara del } \\
\text { s }^{\text {mo }} \text { sacramento } \\
14 »\end{array}$ & $\begin{array}{l}\text { Inc.: «Pues que quedais } \\
\text { desposada...» }\end{array}$ & p. 166 & $\begin{array}{l}\text { [14] Professió de Clara } \\
\text { del Santíssim Sagrament } \\
\text { Granollacs }\end{array}$ \\
\hline [18] & «Otras» & $\begin{array}{l}\text { Inc.: «Pues del grande } \\
\text { hemanuel...» }\end{array}$ & p. 166 & $\begin{array}{l}\text { Sense referència. } \\
\text { Clara del Santíssim } \\
\text { Sagrament Granollacs }\end{array}$ \\
\hline [19] & «Otras. 15a» & Inc:: «Pues que ya sois clara...» & p. 167 & $\begin{array}{l}{[15] \text { Sense referència. }} \\
\text { Clara del Santíssim } \\
\text { Sagrament Granollacs }\end{array}$ \\
\hline [20] & $\begin{array}{l}\text { «Otras para el } \\
\text { velo» }\end{array}$ & $\begin{array}{l}\text { Inc.: «Pues que clara sois } \\
\text { velada...» }\end{array}$ & p. 167 & $\begin{array}{l}\text { Vel de } \\
\text { Clara del Santíssim } \\
\text { Sagrament Granollacs }\end{array}$ \\
\hline [21] & $\begin{array}{l}\text { «A la profesion de } \\
\text { la her }{ }^{\text {na }} \text { teresa de } \\
\text { jesus coplas } 16 »\end{array}$ & $\begin{array}{l}\text { Inc.: «Bendesid sienpre al } \\
\text { señor...» }\end{array}$ & pp. 167-168 & $\begin{array}{l}\text { [16] Professió de Tresa de } \\
\text { Jesús Meca Vilana }\end{array}$ \\
\hline [22] & $\begin{array}{l}\text { «Al velo de la her }{ }^{\mathrm{na}} \\
\text { teresa de Jesus } \\
\text { coplas } 19 »\end{array}$ & Inc.: «el artifice del cielo....» & pp. $169-170$ & $\begin{array}{l}{[19] \text { Vel Tresa de Jesús Meca }} \\
\text { Vilana }\end{array}$ \\
\hline [23] & $\begin{array}{l}\text { «coplas al abito de } \\
\text { la her }{ }^{\text {na }} \text { catalina de } \\
\text { xpo } 20 »\end{array}$ & Inc.: «Oy la magestad divina» & pp. 170-171 & $\begin{array}{l}\text { [20] Hàbit de Caterina de } \\
\text { Crist }\end{array}$ \\
\hline [24] & «Otras. 21a» & $\begin{array}{l}\text { Inc.: «P.: Qué buscáys con tal } \\
\text { contento...» }\end{array}$ & p. 171 & $\begin{array}{l}\text { [21] Sense referència. } \\
\text { Caterina de Crist [s.n.] }\end{array}$ \\
\hline [25] & $\begin{array}{l}\text { «22 Al ponerle la } \\
\text { corona» }\end{array}$ & $\begin{array}{l}\text { Inc.: «La corona os dan con } \\
\text { gozo...» }\end{array}$ & p. 171 & $\begin{array}{l}\text { [22] Sense referència. } \\
\text { Caterina de Crist. } \\
\text { Incompleta. }\end{array}$ \\
\hline
\end{tabular}

